\title{
USE OF WASTE FOR ENERGY APPLICATIONS
}

\author{
Erik Dahlquist \\ Kurt Hansson \\ Eva Thorin \\ Fredrik Wallin \\ Mälardalen University, Sweden
}

\begin{abstract}
In Sweden the utilization of household waste for energy purposes is quite significant already today. Individuals sort the household waste in different fractions where the organic biologically degradable material is separated into one fraction, while other type of combustible materials into one or more fractions. The rest of the waste is normally going to recycling, like metal, glass and paper. Concerning industrial waste we have a similar situation.

In Vastmanland and eastern Uppland a collection system with sorting of waste into many fractions has been in operations for 15 years. This has led to a situation, where most waste is sorted in a very good way. Just $1-2 \%$ of the waste is put into the wrong container. At the central waste recycling plant at Gryta in Vasteras, the biologically degradable organic waste is mixed with fat sludge from restaurants and lay crops like clover and grass into a large biogas reactor. This now has been in operations for four years. It has been proven that the residue from the reactor is not causing any problems with heavy metals or organic toxics when used as fertilizer, and the residue is actually even CERALIA and KRAV certified.

When it comes to extension of biogas production, we are running into a shortage of feed stocks generally in most cities in Sweden. It therefore becomes more interesting to utilize more agricultural wastes like straw, but also to introduce high temperature gasification for e.g. methane production. Today most recycled wood and similar is combusted. This gives heat, but unfortunately no organic materials to the farmlands. We also see a trend towards low energy buildings reducing the need for heat, while the wish to replace fossil fuels for transportations is increasing.

In Västmanland and other parts of Sweden high temperature gasification processes with circulated fluidized beds (750-900 oC) as well as CORTUS high temperature processes using steam for the actual gasification at $1100 \mathrm{oC}$ are investigated. These techniques are also discussed in the paper.
\end{abstract}

\section{KEYWORDS}

Waste, energy, utilisation

https://doi.org/10.15626/Eco-Tech.2010.112 
Linnaeus ECO-TECH '10

Kalmar, Sweden, November 22-24, 2010

\section{INTRODUCTION}

40 years ago Sweden was utilizing some 50 TWh of biomass per year. Almost all was within the pulp and paper sector, where $30 \mathrm{TWh}$ was black liquors and 15 TWh bark and other type of residues. Only approximately $5 \mathrm{TWh} / \mathrm{y}$ was used for other purposes. Since then we have seen a tremendous increase in the utilization of biomass in all forms and 2009 the total utilization was around $132 \mathrm{TWh}[1]$ and to this we can add also organic waste.

We have 2690000 ha agriculture area. With 5.3 ton cereal/ha +5 ton straw at $5.4 \mathrm{MWh} /$ ton this gives $150 \mathrm{TWh} /$ year. If we consider the straw as waste, half or $75 \mathrm{TWh} / \mathrm{y}$ can be considered as agricultural waste today. With new crops and focus on biomass production 200$250 \mathrm{TWh} / \mathrm{y}$ total biomass could be possible, and most of this can be considered as energy crops or wastes - that is not to be used as food. The total amount available for energy utilization then would be some $150 \mathrm{TWh} / \mathrm{y}$.

We also have 27000000 ha forests * 2 ton DS/ha,y * 5,4 MWh/ton $=293 \mathrm{TWh} / \mathrm{y}$. There should be a potential to increase the forestry production with some $50 \%$ long term, giving $440 \mathrm{TWh} / \mathrm{y}$. This can be utilised in different ways. If all was to be used for paper production roughly half could be used as black liquors as as bark etc for energy purposes. All this could principally be gasified and then used for both vehicle fuels and for electricity and heat production. This corresponds to some 200-300 TWh/y.

If we add them together we should have some $350-450 \mathrm{TWh} / \mathrm{y}$ of principally waste biomass, or more than the total energy utilization today (approximately $400 \mathrm{TWh} / \mathrm{y}$ ). If we then consider that we also produce some $70 \mathrm{TWh} / \mathrm{y}$ of hydro power and have a goal to produce $30 \mathrm{TWh}$ wind power per year by 2030, the energy situation in Sweden looks very positive, with a major possibility for export. If Sweden decides to replace the existing nuclear power we can add another $70 \mathrm{TWh} /$ year of electric power.

In EU power generation from Biomass/waste is predicted [2] to go from $84 \mathrm{TWh} 2005$ to 120 2010, 171 2015, 261 2020, 2752025 and then level out at 2862030 . By $202020 \%$ of the energy used in EU should be renewables, and the major portion of this will be biomass, corresponding to some $3000 \mathrm{TWh} / \mathrm{y}$.

Approximately $47 \%$ of all house hold waste in Sweden is combusted today [3], producing both heat and electric power. Still, only $0.3 \%$ of the total electric power production comes from this! Large amounts of waste is also imported from Europe, as it is still no cost to purchase waste aside of transportation and handling. The fly ash is some 3-5\% of the fuel fed to the combustor and $15-20 \%$ is coming out as bottom ash, which goes to a deposit pit or is recycled in some way. The house hold waste normally contains some 30-45 \% moisture and the efficient heating value is around $3 \mathrm{kWh} / \mathrm{kg}$. In household waste their is normally no plastics, while in industrial waste and mixed waste around $10 \%(5-15 \%)$ of different plastics is typical. We have made analysis on some wastes and made moisture and content of PVC, PE, PS and PUR with good accuracy using NIR-spectroscopy [4].

\section{BIOGAS PRODUCTION}

According to [5] the total amount of biogas was 1.4 TWh 2008 from 227 plants. The total production was 225 million $\mathrm{m} 3$ biogas corresponding to154 million $\mathrm{m} 3$ methane. From these plants 140 are at waste water treatment plants, 58 at waste depots, 17 as co-fermentation, 4 at industries and 8 at single farms. The total amount of plants for upgrading of the gas - that is 
remove $\mathrm{CO}_{2}$ - was 37. At seven sites also the gas was injected into an existing fossil gas network.

$44 \%$ of the gas was produced at the waste water treatment plants, $27 \%$ at the depots and $18 \%$ in co-fermentation plants. $53 \%$ of the gas was used primarily for heating purposes, while only $26 \%$ was used for transportation purposes. $59 \mathrm{GWh}$ electricity was produced corresponding to $4 \%$ and $14 \%$ was just burned off, that is wasted, due to normally handling problems. The co-fermentation plants also produced 375932 ton bio-fertilizers for use to enhance the soil structure. From the single farms 37125 ton was produced.

There is a national goal to be independent of fossil fuels for vehicles by 2030. Biogas is here very important as the major alternative fuel. In combination with series hybrid vehicles consuming probably not more than $0.1-0.21$ fuel $/ 10 \mathrm{~km}$ by then, the total need for personal vehicles could be reduced from today's $50 \mathrm{TWh} / \mathrm{y}$ to probably around $5-10 \mathrm{TWh} / \mathrm{y}$, and then biogas could replace all. The increased electricity demand then can be covered by wind and solar as well as cogeneration using biomass. If we also want to replace the fuels for heavy vehicles, we should probably need another 15-20 TWh/year. Then high temperature gasification of solid wastes would be needed as well, discussed in next chapter.

There is a strong expansion of new plants using crops and wastes from agriculture right now. If we look at an example from Västmanland we have today production of biogas in the Växtkraft biogas plant corresponding to ca $430 \mathrm{~m} 3$ petrol from lay crops at 130 ha farm land area. Totally we had ca 28000 ha available land area (grace land) in 2008, to produce 93000 $\mathrm{m} 3$ petrol equivalents. This corresponds to ca $0.93 \mathrm{TWh}$ methane ("petrol"). The total consumption of fossil fuels today is $2-2.4 \mathrm{TWh} / \mathrm{y}$. With the new type of series hybrids and electric vehicles the need would probably be somewhere around $0.5-0.8 \mathrm{TWh} / \mathrm{y}$. This would cover all fuels needed in county Västmanland with new plug-in vehicles. When this can be achieved will depend on the driving forces. Driving forces will be the profitability for those doing the investments in the production facilities and for the farmers who should deliver the crops and use the produced soil fertilizers.

Of course we can always discuss if lay crops is waste or not. To our opinion we would use that nomenclature, as the main purpose is to produce primarily $\mathrm{N}$ - nutrients and enhancements for the soil structure, and these are produced also if the crops are first fermented.

\subsection{Liquid phase reactors}

At Växtkraft in Västerås [6] household waste and lay crops are fermented together. 14000 ton sorted organic household waste with $30 \%$ DS corresponding to some 4200 ton ds is mixed with 4000 ton fat sludge with $4 \%$ DS from oil separators at restaurant kitchens corresponding to 160 ton DS. Later on this is mixed with 5000 ton ensilage from clover rich crops from 300 ha contracted land, $35 \%$ DS. Harvest is done 2-3 times/y. This gives some 1750 ton DS per year. The production is approximately $15000 \mathrm{MWh}$ methane gas, corresponding to 1500000 litre petrol.

Biogas from the sewage plant fermentor in Västerås gives another $8000 \mathrm{MWh}$, corresponding to approximately 800000 litre petrol. The total production from the upgrading plant then becomes $2300 \mathrm{~m} 3$ "petrol" or ca $23000 \mathrm{MWh}$ gas for vehicles. Waste residuals are recycled to farm land containing 150 ton Nitrogen, 30 ton phosphor and 100 ton Potassium aside of organic materials that are enhancing the soil structure. As there is a careful sorting and 
separation upfront the fermentor the quality of the return sludge is guaranteed even by KRAV and CERALIA.

As well as we have a need for new feed stocks to the reactors, we need to improve the performance of existing ones. Pre-treatment of materials have been shown give significant increased production of gas compared to if no pre-treatment was done. Up to twice as much gas has been produced from the same amount of biomaterial after e.g. electroporation treatment. Also steam explosion and hydrolysis has proven to give high effect on especially harder materials. Also mixing in the reactor is of importance, as otherwise the reactions are prohibited due to build up of high concentrations of products. Sometimes it may also be difficult to run with only the same type of substrate all the time. Restrictions will be on e.g. trace elements. By combining different type of feed stocks then can give much higher yields than running with only one feed stock.

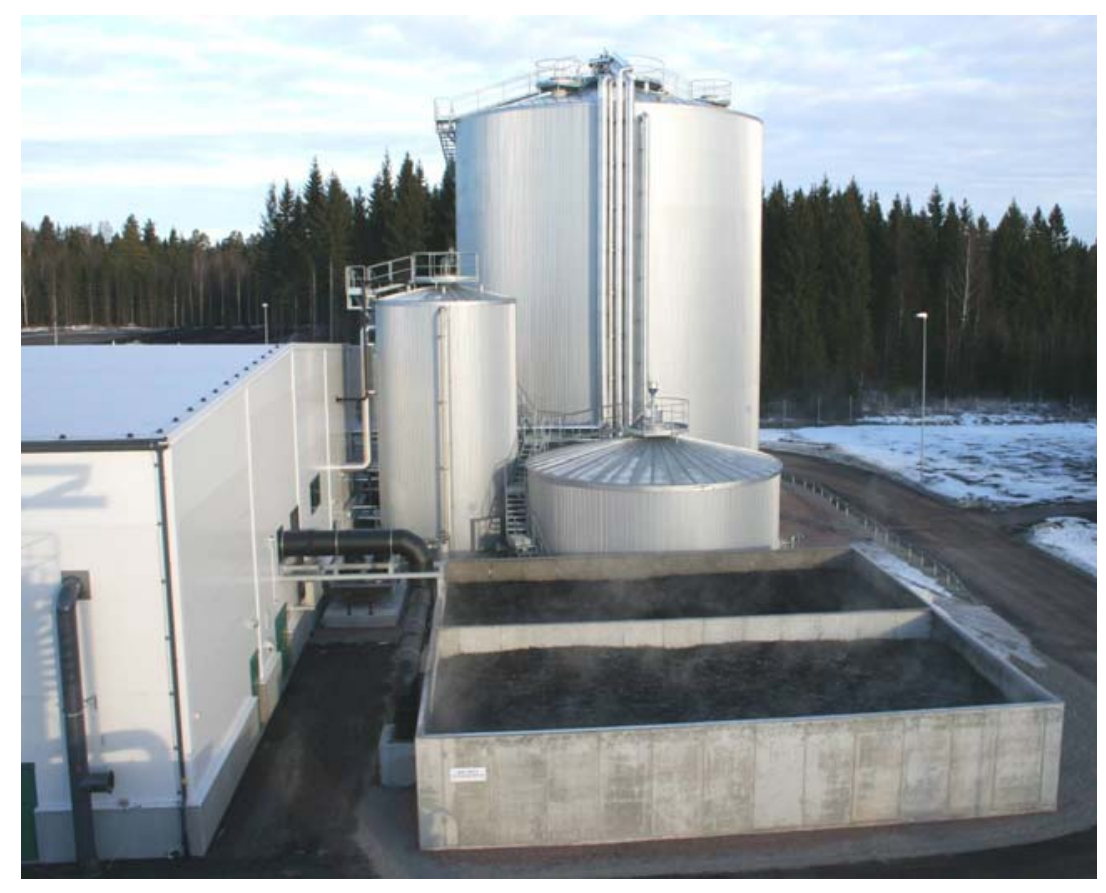

Figure 1. The Växtkraft liquid phase biogas reactor, $4000 \mathrm{m3}$..

\subsection{Solid phase reactors}

For single farm plants the liquid phase reactor may be too complicated and then solids phase reactors is a good alternative. Outside Sala a slowly rotating $100 \mathrm{~m} 3$ reactor is operating on lay crops together with cow manure as the "starter. The goal is to produce some $300 \mathrm{~m} 3$ gas per day. Here the feed is not mixed with water at all, but the feed stock of lay crops mixed with already fermented material coming out of the reactor. Some ammonia is produced and separated at high concentration to be used as a liquid fertilizer. The surplus solid residue is distributed to enhance the soil structure as well in the farm land that is mainly used for production of cereals, aside of the rotating lay crop production. The reactor can be seen in figure 2 . 


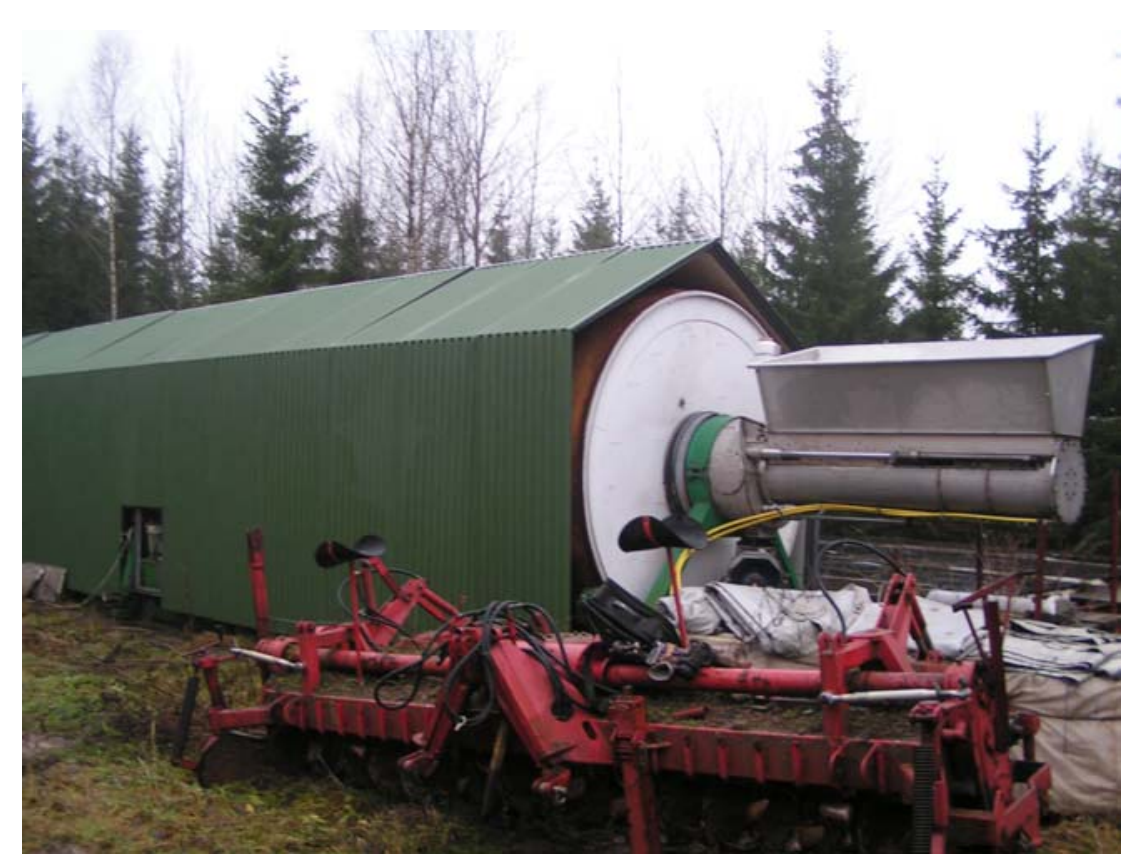

Figure 2. The solid phase reactor for biogas production from lay crops outside Sala.

\section{HIGH TEMPERATURE GASIFICATION}

As already mentioned in the introduction, there is a huge potential to use solid waste to produce heat and chemicals, as well as electric power. DONG Energy in Denmark use 700 000 ton straw/y in power plants already today $(3.5 \mathrm{TWh} / \mathrm{y})$, and other companies use almost the same amount as well. In Sweden straw is used rarely for energy purposes due to low experience in how to combust in an efficient way without running into problems with fouling. Both straw and other biomass as bark etc could be utilized also in gasifiers, and thereby produce also methane or other products. The gas

\subsection{Very high temperature reactors}

If we use high temperature gasification around $1150 \mathrm{oC}$, the gas will primarily be as $\mathrm{CO}+\mathrm{H}_{2}$ aside of $\mathrm{CO}_{2}$ and $\mathrm{H}_{2} \mathrm{O}$, and no tars will be formed. One example of this type of reactors is the one developed by CORTUS [7]. This has a two step procedure, where biomass is first pyrolysed and the char falling down to a second step, where it reacts with steam at $1150 \mathrm{oC}$ to produce a very energy rich syn-gas. The pyrolysis gas and/or liquids are combusted to give the heat driving the steam gasification. With this technology a tar free gas is produced that could be converted in e.g. a Fischer- Tropsch process to produce methane, DME or methanol. Alternatively the gas can be used in e.g. lime kilns, where $\mathrm{CaCO}_{3}$ is converted into $\mathrm{CaO}$ at high temperatures.

A 5 MW plant is right now being projected by CORTUS in Köping to produce gas which will be utilized in the lime kiln at Nordkalk to convert $\mathrm{CaCO} 3$ to $\mathrm{CaO}$.

\subsection{Medium temperature reactors}


At low temperatures - that is around 650-700 degrees for black liquors and some $850-900$ degrees for solid biomass - up to more than $50 \%$ of the HHV of the gas can be as methane directly. In this case it is common to use circulating fluidized bed reactors, as we are below the melting point for the major parts of the solids. Several companies have developed processes for black liquor gasification like ABB [8-10], Bioregional minimills in the UK and Chemrec, who are now running a quench reactor at Piteå since several years back.

Concerning solid biomass Metso installed a CFB at Värö for biomass gasification 20 years ago. They are right now building a gasifier system for biomass in Gothenburg that should give $\mathrm{CO}+\mathrm{H} 2$ that will be further converted by Haldor- Topsö into primarily methane and other hydrocarbons. This is a $20 \mathrm{MW}$ gasifier in the Gobi-gas project, and will be followed by a 80 MW later on according to the plans. In Lahti in Finland Metso are also building a $160 \mathrm{MW}$ plant for waste gasification, so Metso can be considered the leading company in biomass and waste gasification today.

At Värnamo a pressurized biomass gasification was built by Ahlström, today Foster-Wheeler. The system is now planned to be upgraded to produce DME, Dimetylether. As soon as one more industrial partner is recruited the project is to take off to demonstrate the complete processes. The dimetyl ether is principally the merger between two methanol molecules by taking away one water molecule. It is a very good fuel for primarily diesel engines and is thus of high interest for heavy vehicles. In China there is a strong drive to produce DME from coal to become independent of oil import. It thus can be expected to be one of the major energy carriers in the future. Also Chemrec are planning a factory to produce DME in Örnsköldsvik, but with their quench reactor. This is also a pressurized system, which is advantageous when it comes to produce chemicals from the gas.

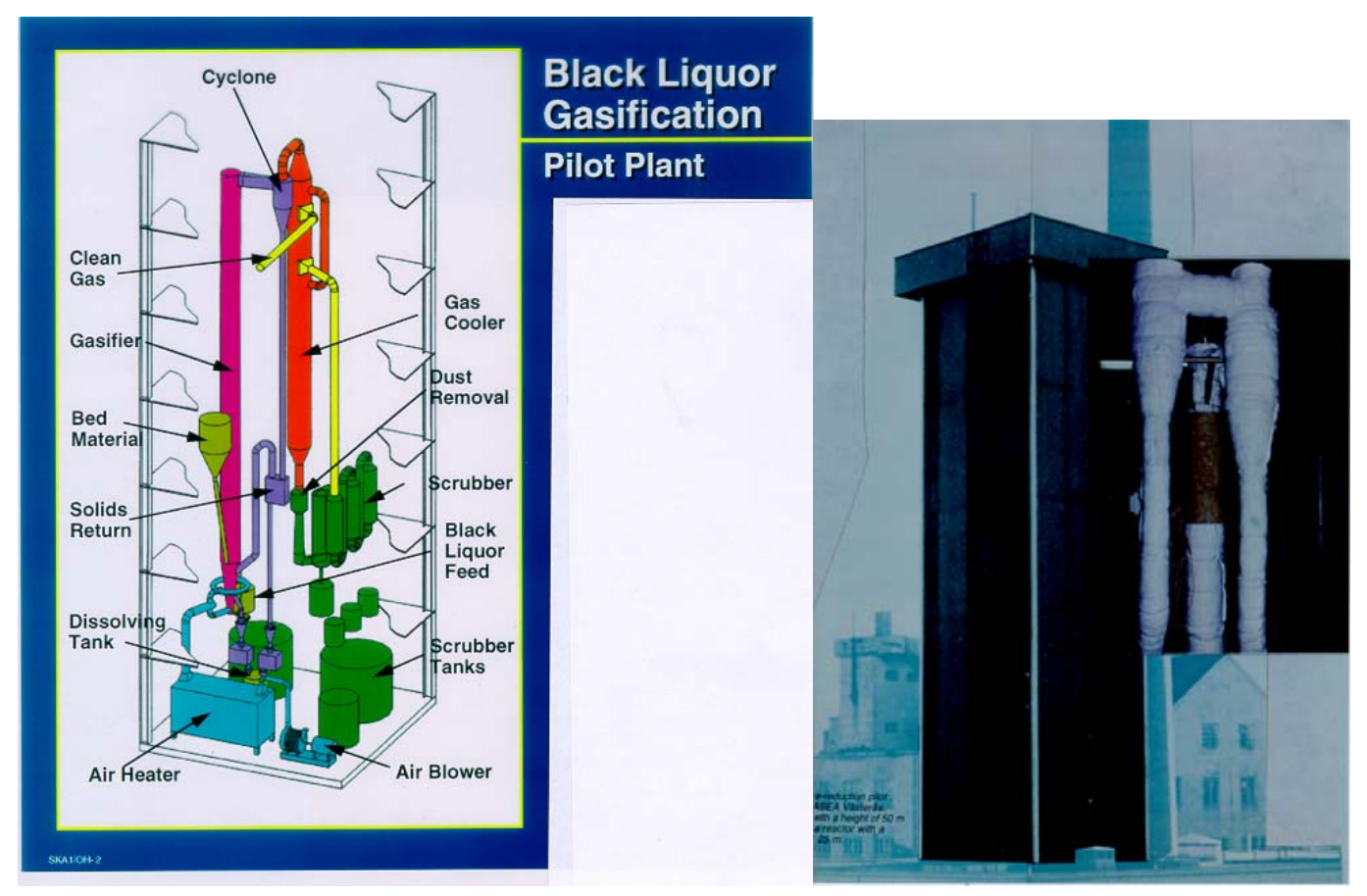

Figure 3. Black liquor pilot gasification plant at ABB in Västerås using a CFB technique with direct caustization. 
The ABB CFB gasifier is a dry gasification process. The bed consist of the original bed solids, maily $\mathrm{Na} 2 \mathrm{CO} 3$, but with the addition of $\mathrm{TiO} 2$ we also can achieve a direct caustization. This means that the $\mathrm{CO} 2$ in the carbonate is stripped off and we form a $\mathrm{Na} 2 \mathrm{O}$.TiO2 solid. When this is leached with water we get $\mathrm{NaOH}+\mathrm{Na} 2 \mathrm{O} .3 \mathrm{TiO} 2$, which is recirculated back to the bed. In this way we can produce $\mathrm{NaOH}$ without needing a lime kiln, which saves a lot of energy and capital investments.

\section{DISCUSSION AND CONCLUSIONS}

There are several different types of waste that can be utilised for energy applications. We have house hold waste, industrial waste, agricultural and forest residues. What is easy to convert in fermentation processes is preferably done so, as we then can produce a good soil enhancement substance. This is important to keep the soils in good shape long term.

What cannot be converted in fermentation is preferably converted in gasification processes instead. Today most of the biomass used in Sweden is combusted to produce heat or heat + electric power. As we make better and better buildings, the heat demand decreases, while we on the other hand have a strong wish to replace fossil fuels by bio-fuels. Here high temperature gasification processes are very interesting. These can produce fuels for vehicles as well as heat and electric power. Several new technologies are being developed right now. Concerning biogas production there is a huge potential to increase this by using new feed stocks, but also to enhance the production in existing plants by pre-treatment of the feed, combining different feed stock materials, and by enhancing mixing and other mechanical factors of importance.

\section{REFERENCES}

13. Swedish energy agency statistics 2010 .

14. Waste Sweden (Avfall Sverige.) (2009). http://www.avfallsverige.se/m4n?oid=1455\&_locale=1 Downloaded dec 2009.

15. Capros P., L. Mantzos, N. Tasios, A. De Vita, N. Kouvaritakis: EU energy trends to $2030-$ UPDATE 2009 EUROPEAN COMMISSION Directorate-General for Energy in collaboration with Climate Action DG and Mobility and Transport DG. 4 August 2010.

16. Larsson H. And Al-Rawi M.: NIR-spectroscopy on solids recycled fuels. Diploma work Mälardalen University, July 2010.

17. Production and use of biogas 2008. In Swedish. ES2010:01. ISSN 1654-7543. Swedish Energy Agency.

18. http://www.vafab.se/om_vaxtkraft_s105.html web page for Växtkraft biogas production plant.

19. http://www.cortus.se/ webpage for Cortus

20. Dahlquist E. and Bob Jacobs : Development of a Dry Black liquor gasification process. Pulp and Paper Canada 95:2(1994)p73-74,.

21. Dahlquist E. and Jones A.: Presentation of a dry black liquor gasification process with direct caustization. TAPPI Journal, June 2005, p 15-19. Awarded best peer reviewed research paper 2005 by TAPPI Journal.

22. Dahlquist E: Modelling and design of a dry black liquor gasification process . IFAC workshop on Applications of Large Scale Industrial Systems (ALSIS) August 30-31, (2006) Helsinki. 